Volume: 11 Issue: 1 Year: 2014

\title{
Effect of Turkish music that premature infants are made to listen during care on stress, oxygen saturation level and length of hospital stay ${ }^{1}$
}

\author{
Diler Aydın ${ }^{2}$ \\ Suzan Y1diz ${ }^{3}$
}

\begin{abstract}
Research was planned as an experimental study in order to determine the effect of Turkish music performance applied during care in the neonatal intensive care unit on stress indicators, oxygen saturation, peak heart rate, respiration value and length of hospital stay. It was an experimental study (experimental n: 30; control n: 30). Preterm infants were made to listen Turkish music for 30 minutes every day. Stress indicators, oxygen saturation, peak heart rate and respiration values observed prior to the care and during 30-minute Turkish music session were registered in the Patient Follow-up Form. No significant decrease was observed in the lengths of hospital stay, oxygen saturation levels and stress levels of babies in the experiment and control groups. It was also seen that peak heart rates and respiration values did not vary. As a conclusion, it was determined that Turkish music which preterm babies staying in the neonatal intensive care unit were made to listen did not affect peak heart rates and respiration values statistically significantly and they were normal. It was also seen that stress indicators were not affected.
\end{abstract}

Keywords: Neonatal intensive care; Oxygen saturation; Stress; Preterm; Turkish music.

\section{Introduction}

Music is an art which expresses emotions and opinions via sounds or expresses sounds in an order and aesthetic way (Gencel, 2006). It is known as the expression way of emotions and information in the history of humankind. It can make a therapeutic effect on its own. It can also lead to psychophysiological changes by sometimes stirring up and stimulating or sometimes

\footnotetext{
1 This study was funded by Istanbul University Scientific Research Projects Unit. Project No: 3251.

2 Phd, RN, Assist. Prof.; Balikesir University, Bandirma School of Health, dileraydin@gmail.com

3 Profesor, Istanbul University, Florence Nightingale Nursing Faculty, Pediatrics Nursing Department, suzyil58@gmail.com
} 
Aydın, D. \& Yildız, S. (2014). Effect of Turkish music that premature infants are made to listen during care on stress, oxygen saturation level and length of hospital stay. International Journal of Human Sciences, 11(1), 1343-1359. doi: 10.14687/ijhs.v11i1.2701

relaxing. In some cases, music may not be used only as a therapy means but can make great benefits for individuals as a protective method (Somakci, 2003).

Music has been used in treating many diseases for years in order to increase happiness/welfare and decrease pain/ache (Somakci, 2003; Coban, 2005; Gencel, 2006). Its use in health sector and social life is increasing gradually. Music therapy is an intervention still used for patients of all age groups including babies, children, adults and the old.

Neonatal Intensive Care Unit (NICU) is an environment where environmental and human sounds are really intense. At a NICU, such many stress behaviors as stress, overstimulation, scare as well as physiological changes in heart rate, oxygen saturation, blood pressure, intracranial pressure and corticosteroid hormone are observed due to undesired noise (Altuncu et al,. 2009; Chen et al., 2009). Music plays a energizing, relaxing and stimulating role at NICU by suppressing this undesired noise (Hodges and Wilson, 2010). Music therapy is used at NICU as a method which reduces stress (Keith and Russell, 2009; Aydin and Yildiz, 2012), facilitates growth (Standley, 2000; Ahmadshah et al., 2010), facilitates transition to feeding, alleviates pain, facilitates sleeping and makes positive changes in oxygen saturation level (SO2) and peak heart rate (PHR) values (Morris et al., 2000; Kemper and Danhauer, 2005; Arnon et al., 2006) and decreases the length of hospital stay (Butt, 1998; Dagoglu, 2002; Mazer, 2010; Hodges and Wilson, 2010; Gilad and Arnon, 2010; Bradt et al., 2010; Thiel et al., 2011).

Music genre which is used in the studies for the aforementioned purposes typically is classical music (Jenkins, 2001; Lubetzky et al., 2010; Aydin and Yildiz, 2012). However, some studies indicate that music genres which neonatals listen during pregnancy of the mother and belong to their own culture affect them more positively (Nair et al., 2003). In our country, there is no study examining the effects of Turkish music on neonatals.

\section{Purpose}

This study was planned in order to evaluate the effects of Turkish music which was played during care at NICU on stress indicators, SO2, PHR, respiration and length of hospital stay values of premature infants.

\section{Hypotheses of the research:}

Hypothesis 1: Reduces stress indicators.

Hypothesis 2: Increases oxygen saturation levels.

Hypothesis 3: Keeps peak heart rates at balance. 
Aydın, D. \& Yildız, S. (2014). Effect of Turkish music that premature infants are made to listen during care on stress, oxygen saturation level and length of hospital stay. International Journal of Human Sciences, 11(1), 1343-1359. doi: $10.14687 /$ ijhs.v11i1.2701

Hypothesis 4: Keeps respiration values at balance.

Hypothesis 5: Decreases the length of hospital stay.

\section{Method and material}

\subsection{The place and time of the study}

Research was carried out at NICU of a university hospital between December 2009 and March 2011.

\subsection{Population and sample selection}

During the research, a total of 507 preterm infants were admitted at NICU and 62 preterm infants were included in the research. 1 preterm infant was excluded from the experimental group due to intracranial bleeding while 1 preterm infant was excluded from the control group due to sepsis. A total of 60 preterm infants were included in the research, 30 of whom were included in the experimental group while 30 of which were included in the control group.

Selection Criteria: The criteria determined to ensure unifomity among experiment and control groups in terms of SO2, PHR and respiration values as well as characteristics that may affect the length of hospital stay included weighing between 1000-1500g, stability at the first postnatal 24 hours, no congenital abnormality, no cranial bleeding, not being intubated, not having hyperbilirubineria which requires blood replacement, not having family members who have hearing problems since childhood and belonging to the Turkish culture.

\subsection{Type of study}

Research was planned as an experimental study in order to determine the effects of Turkish music which preterm infants were made to listen during the care applied at NICU on stress indicators, oxygen saturation, peak heart rate, respiration value and length of hospital stay (PretestPosttest, Control Group Pattern).

\subsection{The variables}

Dependent variable of the research is Turkish music while the independent variables are oxygen saturation, peak heart rate, respiration values and length of hospital stay.

\subsection{Data collection}

\subsubsection{Data collection method}

\section{Experimental group}

1st Phase: Researchers waited the preterm infants who were brought to the neonatal intensive care unit and complied with the case selection criteria to become stable. Families of the infants who were stable and were not intubated at the first 24 hours were consulted and asked whether they wanted to take part in the research. Written permissions were taken from the parents who accepted 
Aydın, D. \& Yildız, S. (2014). Effect of Turkish music that premature infants are made to listen during care on stress, oxygen saturation level and length of hospital stay. International Journal of Human Sciences, 11(1), 1343-1359. doi: $10.14687 /$ ijhs.v11i1.2701

to participate in the research. Parents were consulted during their visit to the infant. Talking to the parents for permission and filling in the form took 10-15 minutes. "Introductory Form about the Infant" was filled in within 5 minutes for infants complying with the case selection criteria. Information forms introducing the infants were enumerated from 1 to onwards. Forms enumerated with uneven numbers were included in the experimental groups while forms enumerated with even numbers were included in the control group.

2nd Phase: As there was not a general music system within the unit, music system was establihsed at the incubators of preterm infants in experimental group. Appropriate conditions were maintained by the firm from which the music system was bought. Researcher receiveda training in this respect and music system was established by the researcher at the incubators. 2 speakers were put in the direction of toes of the infant. A distance of about 30 cantimeters was left between the speakers and the infant. Noise (decibel) measurement device was connected to the eletricity power on the baby counter outside the incubator. Microphone of the device was place between the speakers in the incubator to measure the sound level within the incubator. Sound level was adjusted to 45 decibels at maximum. Attention was paid to prevent interference with the sound level of MP4. All the equipments were disinfected in line with the instructions of Infection Control Committee before they were used in another patient.

3rd Phase: Prior to the research, nurses of the unit were informed about the research, music system and its functioning. At NICU, preterm infants are followed up routinely at 3-hour intervals a day. Routine follow-up of preterm infants includes fever, PHR, respiration, SO2, tension, aspiration if necessary, mouth, eye, skin, umbilicus, wound controls and cares as well as feeding. During routine follow-up, monitoring takes 10-15 minutes, care takes 10 minutes and feeding takes 10 minutes. One of the care sessions of nurses was selected (the longest care session taking place afternoon). Infant was evaluated prior to the care and stress indicators, SO2, PHR and respiration values observed 1 minute before the care were recorded in the Patient Follow-up Form. Music was played and care was started. Music lasted for almost 30 minutes. At the end of 30 minutes, stress indicators of the infant were observed and SO2, PHR and respiration values were recorded once more. During the music session, infant was left alone to prevent influence over the infant's stress indicators, SO2, PHR and respiration values. No intervention was allowed except for the care practices. Preterm infants were made to listen Turkish music for 30 minutes three days a week for routine follow-up until discharge. However, researcher recorded the data while preterm infants were listening to Turkish music two times a week. 
Aydın, D. \& Yildız, S. (2014). Effect of Turkish music that premature infants are made to listen during care on stress, oxygen saturation level and length of hospital stay. International Journal of Human Sciences, 11(1), 1343-1359. doi: $10.14687 /$ ijhs.v11i1.2701

\section{Control Group}

Control group also underwent the same phases as the experimental group and it was followed up two times a week by the researcher and the relevant data were recorded. No difference was that preterm infants in the control group were not made to listen Turkish music.

\subsubsection{Data collection tools}

In collecting the data, "Patient Approval Form" which was developed by the researcher to receive the written permissions of the families, "Introductory Form about the Infant" which includes characteristics introducing the preterm infants (sex, weight at the time of hospitalisation, body height, head circumference, diagnosis and status of hearing problem) and " Patient Follow-up Form" where SO2, PHR, respiration, stress values of preterm infants were recorded before and after the music therapy were used.

During the research, digital infant scale, MP4, speaker, sound decibel measurement device (sound level was adjuested to 45 decibels at maximum), classical Turkish music CD (TÜMATATurkish Music Research and Promotion Group's Dede Efendi Music CD) were used. The mode of Rast which is known to give happiness, joy, peace and bliss, to be beneficial to spastic and autistic children, to be effective for head and eyes and to prevent stress in children was used in the music CD of Dede Efendi. Musical instruments used in the CD included reed flute, rebab, lute and dombra. Sounds of water and river, nightingale, horse walking, sheep, laughing children, cicada, bird, smiling baby, playing children and whale were used in the research as effects.

In assessing the stress indicators in the research, stress levels included in the individualized developmental care were used. Stress levels are given in the Table 1.

Table 1. Stress levels

\begin{tabular}{lll}
\hline Mild & Moderate & Severe \\
\hline $\begin{array}{l}\text { Disturbance from eye contact } \\
\text { Turning right and left }\end{array}$ & $\begin{array}{l}\text { Blush } \\
\text { Colour changes in the body }\end{array}$ & $\begin{array}{l}\text { Paleness } \\
\text { Cyanosis }\end{array}$ \\
Hiccup & Sighing & Tachypnea \\
Grimacing & Regurgitation & Bradypnea \\
Hanging down in the chin & Outwardness of hand fingers & Apnea \\
Closing the eyes & Extension in the arms-legs & In oxygen levels \\
Opening the mouth & Sudden withdrawal movements & Tachycardia \\
Sticking out the tongue & Weakness & Bradycardia \\
Sneezing & & Dysrthymia \\
\hline
\end{tabular}

Coughing

Note: Tari, A. (2003b). Assessment and arrangement of the environment in the neonatal intensive care units. In H. Pek (Ed.), Individualized Supportive Developmental Care in Intensive Care Units Course. Istanbul. 
Aydın, D. \& Yildız, S. (2014). Effect of Turkish music that premature infants are made to listen during care on stress, oxygen saturation level and length of hospital stay. International Journal of Human Sciences, 11(1), 1343-1359. doi: 10.14687/ijhs.v11i1.2701

Preterm infants were given points according to their stress indicators and average stress points were obtained. In calculating the stress points, the points given to infants with no stress, with mild stress indicators, moderate stress indicators and severe stress indicators were $0,1,2$ and 3, respectively (Tari, 2003a; Tari, 2003b).

\subsubsection{Data collection time}

Data were collected between December 2009 and March 2011.

\subsection{Limitations of the study}

Due to the materials used in the context of research is expensive and a single application was made only in a hospital. Different hospitals are not included in the study. Therefore cases was not collected in less time.

\subsection{The generalizability of the study}

Since findings from this study were collected only from an university hospital, they cannot be generalized to the overall population.

\subsection{Research ethics}

Written permissions were received from the relevant institution and Ethical Committee of Cerrahpasa Faculty of Medicine of İstanbul University for the research. Besides, parents of preterm infants complying with the case selection criteria were consulted and asked for their opinion as regards to participating in the research. Their written permissions were also taken through "Informed Approval Form". Parents were assured about the confidentiality of the information. Study was carried out in line with the principles of Helsinki Declaration.

\subsection{Evaluation of data}

SPSS (Statistical Package for Social Sciences) for Windows 12 program was used for statistical analysis of findings of the study. In addition to descriptive statistical methods used to evalute the study data (percentage, average, standard deviation), Student $t$ test was used in intergroup comparisons of parameters showing normal distribution. Paried Sample t test was also used in intragroup comparisons.

Wilcoxon sign test was used in intra group assessments of stress parameters with do not show normal distribution. Besides, Chi-square and Fisher's Exact Chi-square tests were used. Results were evaluated at a confidence interval of $95 \%$ and at a significance level of $\mathrm{p}<0.05$. 
Aydın, D. \& Yildız, S. (2014). Effect of Turkish music that premature infants are made to listen during care on stress, oxygen saturation level and length of hospital stay. International Journal of Human Sciences, 11(1), 1343-1359. doi: $10.14687 /$ ijhs.v11i1.2701

\section{Results}

\section{Findings related to the Introductory Information}

When sexes and gestation week distributions of groups were compared, no statistical difference was observed between the groups $(\mathrm{p}>0,05)$. In the control and experimental groups, there were mostly appropriate for gestational age (AGA) preterms and those with transient tachypnea of newborn (TTN) and respiratory distress syndrome (RDS). No statistically significant difference was detected between the groups in terms of diagnoses of preterm infants $(p>0,05)$. Likewise, no statistically significant difference was found between the groups in terms of the length of hospital stay $(\mathrm{p}>0,05)$.

\section{Results related to the Life Signs}

Life sign measurements of groups were carried out in 2 phases, 1 minute before the care and music session and at the end of the music session (30 minutes).

Table 2. First and last so2 values of groups and comparison of values $(\mathrm{N}=60)$

\begin{tabular}{|c|c|c|c|c|}
\hline \multicolumn{2}{|c|}{$\mathrm{SO}_{2}$ VALUES } & \multirow{2}{*}{$\begin{array}{l}\text { EXPERIMENT }(n=30) \\
\text { Avr. } \pm \text { SS } \\
97.70 \pm 2.29\end{array}$} & \multirow{2}{*}{$\begin{array}{l}\text { CONTROL }(n=30) \\
\text { Avr. } \pm \text { SS } \\
97.56 \pm 2.09\end{array}$} & \multirow{2}{*}{$\begin{array}{l}\mathbf{t} ; \mathbf{p} \\
-0.235 ; 0.815\end{array}$} \\
\hline First $\mathrm{SO}_{2}$ & Before & & & \\
\hline & $30^{\text {th }}$ min. & $97.46 \pm 2.67$ & $97.73 \pm 2.57$ & $0.000 ; 1.000$ \\
\hline \multicolumn{2}{|c|}{$\begin{array}{l}\text { Prior to Care- } \\
\text { At the end of music ( } 30 \text { minutes) }\end{array}$} & ${ }^{+} \mathrm{t}: 0.508 ; \mathrm{p}: 0.615$ & ${ }^{+} \mathrm{t}:-0.404 ; \mathrm{p}: 0.689$ & \\
\hline \multirow[t]{2}{*}{ Last $\mathrm{SO}_{2}$} & Before & $97.12 \pm 2.92$ & $97.12 \pm 3.81$ & $-0.379 ; 0.705$ \\
\hline & $30^{\text {th }}$ min. & $97.88 \pm 2.40$ & $98.00 \pm 2.57$ & $-0.375 ; 0.705$ \\
\hline \multicolumn{2}{|c|}{$\begin{array}{l}\text { Prior to care- } \\
\text { At the end of music }(30 \mathrm{~min} \text {.) }\end{array}$} & ${ }^{+} \mathrm{t}:-1.695 ; \mathrm{p}: 0.103$ & ${ }^{+} \mathrm{t}:-0.879 ; \mathrm{p}: 0.388$ & \\
\hline
\end{tabular}

As seen in Table 2, when first and last SO2 measurements of experiment and control groups were compared in terms of values obtained prior to care and at the 30th minute, it was detected that there was no statistically significant difference between the average SO2 values of groups prior to care and at the 30th minute.

When average values of the first SO2 measurements of experiment and control groups taken prior to care and at the 30th minute were examined separately within the groups, it was seen that there was no statistically significant difference between them.

When average values of the last SO2 measurements of experiment and control groups taken prior to care and at the 30th minute were examined separately within the groups, it was seen that there was no statistically significant difference between them. 
Aydın, D. \& Yildız, S. (2014). Effect of Turkish music that premature infants are made to listen during care on stress, oxygen saturation level and length of hospital stay. International Journal of Human Sciences, 11(1), 1343-1359. doi: 10.14687/ijhs.v11i1.2701

Table 3. First and last average PHR values of groups and comparison of values $(\mathbf{N}=60)$

\begin{tabular}{|c|c|c|c|c|}
\hline \multicolumn{2}{|c|}{$\begin{array}{l}\text { PHR Values } \\
\text { (number/min) }\end{array}$} & \multirow{2}{*}{$\begin{array}{l}\text { Experiment }(n=30) \\
\text { Avr. } \pm \text { SS } \\
144.93 \pm 12.23\end{array}$} & \multirow{2}{*}{$\begin{array}{l}\text { Control }(n=30) \\
\text { Avr. } \pm \text { SS } \\
142.76 \pm 24.49\end{array}$} & \multirow{2}{*}{$\begin{array}{l}\mathbf{t} ; \mathbf{p} \\
0.301 ; 0.643\end{array}$} \\
\hline First PHR & Before & & & \\
\hline & $30^{\text {th }}$ min & $143.96 \pm 13.44$ & $144.63 \pm 12.67$ & $0.198 ; 0.844$ \\
\hline $\begin{array}{l}\text { Prior to carc } \\
\text { At the end } \mathrm{C}\end{array}$ & ic (30 minutes) & ${ }^{+}$t: $0.436 ; \mathrm{p}: 0.666$ & ${ }^{+} \mathrm{t}:-0.478 ; \mathrm{p}: 0.636$ & \\
\hline \multirow[t]{2}{*}{ Last PHR } & Before & $142.64 \pm 12.01$ & $144.93 \pm 12.33$ & $-1.061 ; 0.289$ \\
\hline & $30^{\text {th }}$ min & $140.00 \pm 14.48$ & $143.96 \pm 13.44$ & $-1.271 ; 0.204$ \\
\hline \multicolumn{2}{|c|}{$\begin{array}{l}\text { Prior to care- } \\
\text { At the end of music ( } 30 \text { minutes) }\end{array}$} & ${ }^{+} \mathrm{t}: 0.817 ; \mathrm{p}: 0.422$ & ${ }^{+} \mathrm{t}: 0.483 ; \mathrm{p}: 0.634$ & \\
\hline
\end{tabular}

As seen in Table 3, when the first and last PHR measurement values of experiment and control groups were compared, it was seen that there was no statiscally significant difference between the first and last measurement values of the groups.

When average values of the first PHR measurements of experiment and control groups made prior to care and at the 30th minute were examined separately within the groups, it was determined that there was no statistically significant difference between them.

When average values of the last PHR measurements of experiment and control groups made prior to care and at the 30th minute were examined separately within the groups, it was determined that there was no statistically significant difference between them.

Table 4. First and last average respiration values of groups and comparison of values $(\mathrm{N}=60)$

\begin{tabular}{|c|c|c|c|c|}
\hline $\begin{array}{l}\text { RESPIRATION } \\
\text { VALUES } \\
\text { (number/minute) }\end{array}$ & & $\begin{array}{l}\text { EXPERIMENT }(\mathrm{n}=30) \\
\text { Avr. } \pm \text { SS }\end{array}$ & $\begin{array}{l}\text { CONTROL }(n=30) \\
\text { Avr. } \pm \text { SS }\end{array}$ & $t ; p$ \\
\hline \multirow[t]{2}{*}{$\begin{array}{l}\text { FİRST } \\
\text { RESPIRATION }\end{array}$} & Before & $53.53 \pm 5.55$ & $54.03 \pm 7.30$ & $0.299 ; 0.767$ \\
\hline & $30^{\text {th }}$ minute & $53.90 \pm 7.91$ & $55.73 \pm 7.21$ & $0.937 ; 0.352$ \\
\hline \multicolumn{2}{|c|}{$\begin{array}{l}\text { Prior to care- } \\
\text { At the end of music ( } 30 \text { minutes) }\end{array}$} & ${ }^{+}$t:- 0.240 ; p: 0.812 & ${ }^{+}$t:- 1.398 ; p: 0.173 & \\
\hline \multirow{2}{*}{$\begin{array}{l}\text { LAST } \\
\text { RESPIRATION }\end{array}$} & Before & $52.40 \pm 6.97$ & $54.04 \pm 4.79$ & $-0.930 ; 0.353$ \\
\hline & $30^{\text {th }}$ minute & $51.76 \pm 5.01$ & $52.93 \pm 5.33$ & $0.617 ; 0.537$ \\
\hline \multicolumn{2}{|c|}{$\begin{array}{l}\text { Prior to care- } \\
\text { At the end of music ( } 30 \text { minutes) }\end{array}$} & +t: 0.437 ; p: 0.666 & +t: 0.437 ; p: 0.666 & \\
\hline
\end{tabular}


Aydın, D. \& Yildız, S. (2014). Effect of Turkish music that premature infants are made to listen during care on stress, oxygen saturation level and length of hospital stay. International Journal of Human Sciences, 11(1), 1343-1359. doi: $10.14687 /$ ijhs.v11i1.2701

As seen in Table 4, when average values of the first and last measurements of experiment and control groups made prior to care and at the 30th minute were compared, it was detected that there was no statistically significant difference between the first and last measurement values of the groups.

When the first average respiration values of experiment and control groups were examined separately within the groups, it was determined that there was no statistically significant difference between the average respiration values of groups obtained prior to care and at the 30 th minute.

When the last average respiration values of experiment and control groups were examined separately within the groups, it was determined that there was no statistically significant difference between the average respiration values of groups obtained prior to care and at the 30th minute.

\section{Findings related to the Stress Levels}

Table 5. Distribution and comparison of first and last stress points of groups $(\mathbf{N}=60)$

\begin{tabular}{|c|c|c|c|c|c|c|}
\hline \multicolumn{2}{|l|}{ STRESS POINT } & \multicolumn{2}{|c|}{$\begin{array}{l}\text { EXPERIMENT }(n=30) \\
\text { Avr. } \pm \text { SS }\end{array}$} & \multicolumn{2}{|c|}{$\begin{array}{l}\text { CONTROL }(n=30) \\
\text { Avr. } \pm \text { SS }\end{array}$} & \multirow{2}{*}{$\begin{array}{l}\mathbf{t} ; \mathbf{p} \\
0.000 ; 1.000\end{array}$} \\
\hline FIRST STRESS & Before & $2.66 \pm 1.12$ & & $4.13 \pm 8.36$ & & \\
\hline & $30^{\text {th }}$ minute & $2.70 \pm 1.31$ & & $2.83 \pm 1.17$ & & $0.413 ; 0.681$ \\
\hline \multicolumn{2}{|c|}{$\begin{array}{l}\text { Prior to care- } \\
\text { At the end of music }\left(30^{\text {th }} \text { minute }\right)\end{array}$} & Z:- 1.605 & p: 0.109 & Z:- 0.789 & p: 0.430 & \\
\hline \multirow[t]{3}{*}{ LAST STRESS } & Before & & & & & \\
\hline & & $3.28 \pm 1.02$ & & $2.50 \pm 1.28$ & & $-0.259 ; \mathbf{0 . 0 2 4}$ \\
\hline & $30^{\text {th }}$ minute & $2.80 \pm 1.41$ & & $3.08 \pm 1.28$ & & $-0.671 ; 0.502$ \\
\hline \multicolumn{2}{|c|}{$\begin{array}{l}\text { Prior to care- } \\
\text { At the end of music }\left(30^{\text {th }} \text { minute) }\right.\end{array}$} & Z:- 0.106 & p: 0.915 & Z:- 0.892 & p: 0.372 & \\
\hline
\end{tabular}

As seen in Table 5, when average stress points received by experiment and control groups prior to care and at the 30th minute were compared, it was determined that there was no statistically significant difference between the first and last measurement values of groups.

Lower and upper limits of stress points that groups can get are 0 and 3 , respectively.

When the first average stress points of experiment and control groups were examined separately within the groups, no statistically significant difference was found between the average stress points of groups received prior to the care and at the 30 th minute. 
Aydın, D. \& Yildız, S. (2014). Effect of Turkish music that premature infants are made to listen during care on stress, oxygen saturation level and length of hospital stay. International Journal of Human Sciences, 11(1), 1343-1359. doi: 10.14687/ijhs.v11i1.2701

When the last average stress points of experiment and control groups were examined separately within the groups, a statistically significant difference was found between the average stress points of groups received prior to the care and at the 30th minute (p:0.024)

\section{Discussion}

\section{Discussion of Findings related to the Introductory Characteristics of Infants}

Research was composed of 60 preterm infants, 30 of whom were included in the experimental group while 30 of whom were included in the control group. Infants constituting the research group did not have significant difference in terms of sex and gestational week and thus, groups can display a homogeneous distribution in terms of sex and gestational week.

Experiment and control groups mostly have preterm AGAs and preterm infants with TTN and RDS. Lack of difference between groups in terms of diagnoses also shows that they are similar.

\section{Discussion of Findings related to the Length of Hospital Stay}

There are many studies examining the effect of music therapy applied on preterm infants at NICU on the length of hospital stay. In these studies, different musical works which relax the infant, are not disturbingly loud, are of classical genre produced only with instruments, are performed by children/women were preferred as well as traditional lullabies (Caine, 1991; Kaminski, 1996; Schwartz, 1997a; Schwartz, 1997b; Standley, 2001; Almerud \& Peterson, 2003; Wood, 2008; Desquiotz-Sunnen, 2008; Whipple, 2008; Cevasco, 2008; Lubetzky et al., 2010; Gooding, 2010; Standley and Swedberg, 2010; Lee, 2010).

In the literature, some studies showed the positive effect of this therapy on the length of hospital stay of preterm infants at NICU (Cevasco, 2008; Lubetzky, et al., 2010; Gooding, 2010; Standley and Swedberg, 2010) while some studies did not detect any positive effect (Ahmadshah et al., 2010; Aydin and Yildiz, 2012).

Caine observed a decrease in the length of hospital stay at the end of the study where preterm infants were made to listen classical musical works of Mozart, Adagio Karajan and Rosenberg C, traditional lullabies, vocal/media volumes as well as relaxing musical works (Caine, 1991). In the study conducted by Gooding (2010), it was reported that music therapy which had developed in the last 15 years did not only suppress the media volumes but also played a role in behavioral development of preterm infants and reduced the length of hospital stay.

In recent years, health spendings have increased depending on the increase in the rate of preterm deliveries. Preterm infants' average length of stay at NICU is 90 days in the USA and the average cost of related health services is 2 billion dollars a year. Previous researches reported that music therapy led to early discharge of preterm infants and thus, decreased healthcare spendings 
Aydın, D. \& Yildız, S. (2014). Effect of Turkish music that premature infants are made to listen during care on stress, oxygen saturation level and length of hospital stay. International Journal of Human Sciences, 11(1), 1343-1359. doi: 10.14687/ijhs.v11i1.2701

(Keith and Russell, 2009; Standley and Swedberg, 2010). In the study conducted by Standley and Swedberg (2010) on 410 preterm infants with gestational weeks lower than 35 weeks, a decrease was observed in the length of hospital stay.

In the study conducted by Cevasco (2008) on 54 preterm infants and 20 mothers included in the experimental group, it was observed that preterm infants listening to lullabies from their mothers at NICU were discharged 2 days earlier than the preterm infants listening to music through CD but no statistical difference was found between groups (Cevasco, 2008). In the study, child sound, water sound and Turkish music accompanied by such instruments as reed flute and rebab in the mode of Rast were played. This study differs from other studies in terms of the music genre and the duration of the music. Thus, results of this study were mostly interpreted within its specific context.

No statistically significant difference was found between the lengths of hospital stay of experiment and control groups constituting the research group. Average length of hospital stay was determined to be around 29-32 days at both groups. The present study shows similarity to the study of Cevasco (2008) in terms of expected results in the length of hospital stay. Preterm infants in the experimental group were discharged 3 days earlier than the preterm infants of the control group but no statistically significant difference was found between the groups. With these results, hypothesis 6 could not be reached. The fact that preterm infants are discharged several days earlier owing to the relaxing effect of music during the average length of hospital stay lasting for 90 days in the developed countries may show a statistically significance.

Considering the historical background of music therapy, Turkish music has always been used in the treatment of many diseases and for various purposes. Instruments (reed flute, rebab etc.) and modes (Rast, Neva, Saba, Huseyni etc.) used in the Turkish music vary considerably. The effect and influence area of each mode also vary (Somakci, 2003; Coban, 2005; Gencel, 2006). The reason why no significant difference was observed between the length of hospital stay in the experiment and control groups may have been the mode, tempo and rhythm of the selected music as well as the sensitivity of the infant and the mother towards music.

\section{Discussion of Findings related to the Life Signs of Infants}

In the literature, there are some studies which revealed different results in relation to the effects of music therapy applied at NICU's on SO2, PHR and respiration values of preterm infants (Standley, 2000; Morris et al., 2000; Courtnage, 2001; Derebent and Yigit, 2006; Hartling et al., 2009; Kreuger, 2010; Gooding, 2010; Mazer, 2010). 
Aydın, D. \& Yıldız, S. (2014). Effect of Turkish music that premature infants are made to listen during care on stress, oxygen saturation level and length of hospital stay. International Journal of Human Sciences, 11(1), 1343-1359. doi: 10.14687/ijhs.v11i1.2701

When studies conducted on preterm infants at NICU were examined, it was seen that the studies showed variety in terms of the decibel measurement levels, live music or music played through tape, duration and type of music (lullaby, Mozart etc.), whether the music therapy was applied during an intervention, difference of influence areas (SO2, PHR, respiration etc.) and gestational week homogeneity of the preterm group.

In the literature, there is one study which examined the life signs, physical measurements and stress behaviors of preterm infants before and after the care which was provided in company with classical musical works of Mozart (Aydin and Yildiz, 2012). However, there is no identical study where Turkish music was applied. The present study is the first to evaluate the effects of Turkish music played at NICU during the care.

When we classify the existing studies in the literature according to whether the music was live or played through tape and whether the music therapy was applied during an intervention, it is seen that Arnon et al. (2006), Desquiotz-Sunnen (2008), Ahmadshah et al. (2010) made preterm infants listen live music which was played by the music therapists with instruments.

On the other hand, Courtnage (2001), Whipple (2008), Neal (2008) and Hodges and Wilson (2010) used musical works played through tape in their studies.

Besides, the researches conducted by Keith et al. (2009), Butt (1998) and Hartling et al. (2009) evaluated the effects of music therapy during various interventions and practices (phlebotomy, feeding and ventilation etc.).

When studies were grouped according to their influence areas (SO2, PHR and respiration values), a group of researchers argued that the music therapy ensured oxygen saturation in preterm infants and kept PHRs at normal levels (Butt, 1998; Desquiotz-Sunnen, 2008; Whipple, 2008; Keith et al., 2009; Hartling et al., 2009; Ahmadshah et al., 2010). Another group of researchers claimed that no change was observed in the SO' and PHR values or they remained in the normal levels (Courtnage, 2001; Arnon et al., 2006; Neal, 2008; Hodges and Wilson, 2010).

In the study, SO2 values of experiment and control groups varied by $97-98 \%$. No statistically significant difference was found between the SO2 values of experiment and control groups (Table 2). It was seen that SO2 values increased slightly at the beginning owing to the stimulating impact of the music but remained at the normal levels during the hospitalization period lasting for 29-32 days due to the relaxing power of the music therapy. Courtnage (2001), Neal (2008) and Arnon et al. made preterm infants with GA of 32-37 weeks listen live music through tape and evaluated SO2, PHR, respiration values during and after music therapy but no change was observed in the SO2 values in contrary to what was expected. The present study is in parallel to 
Aydın, D. \& Yildız, S. (2014). Effect of Turkish music that premature infants are made to listen during care on stress, oxygen saturation level and length of hospital stay. International Journal of Human Sciences, 11(1), 1343-1359. doi: 10.14687/ijhs.v11i1.2701

these studies in terms of the changes in SO2 values (Courtnage, 2001; Arnon et al., 2006; Neal, 2008). However, none of these researches conducted an intervention on the infant but only played live music or music through tape. When the present study is compared to the abovementioned studies, it is thought that live music or music played via tape did not affect $\mathrm{SO} 2$ values and music therapy during care also did not change the SO2 values of the infant. Music listening habits of infant and mother during pregnancy may also play a role in this result. As a consequence, hypothesis 3 could not be reached.

The literature reports that postnatal heart rate of the infant is above $170 / \mathrm{min}$. and it ranges between 120 and 160/min. after stabilisation (Dagoglu, 2002; Hernandez and Thilo, 2007). These values can vary while the infant is sleeping or is awake. When PHR values were examined in the research, they were found to range between 140 and 144/min. both at the experiment and control groups. It was determined that PHR measurement values were in the normal limits and there was no statistically significant difference between the first and last measurement values of experiment and control groups (Table 3). This may have resulted from the fact that Turkish music played for 29-32 days has different modes, rhythms and tones than the other genres including classical music, lullaby or live music and has no symphonic rises and falls and thus, the infant gets accustomed to the music in a relatively short time. Therefore, this therapy only kept PHR values in the normal limits by preventing a decrease owing to its stimulating effect.

Neal (2008), Ahmadshah et al. (2010) made infants listen lullabies for 20-30 minutes in their stdudies and could not detect any difference between PHR values of experiment and control groups. The present study shows parallelism with the studies of these researchers in terms of PHR values (Neal, 2008; Ahmadshah et al., 2010). These researchers also made infants to listen live lullabies or used tape without any intervention. However, we can argue that Turkish music did not affect the infant as we played music during the care and thus, PHR values remained within the normal limits. Whether the infant listens to a familiar music that she/he got accustomed to listening during pregnancy is thought to have an impact on the results. Hypothesis 4 could not be reached as PHR values remained in the normal limits.

Respiration value of the infant should be $40-60 / \mathrm{min}$. in the general examination findings. However, respiration values are more variable in the preterm infants depending on the status of sleeping and being awake and they tend to experience sleep apnea (Dagoglu, 2002; Hernandez and Thilo, 2007). It was determined that there was no significant difference between the first and last measurement values of experiment and control groups obtained before the care and at the 30th minute (Table 4). Courtnage (2001), Arnon et al. (2006) and Neal (2008) made preterm infants 
Aydın, D. \& Yildız, S. (2014). Effect of Turkish music that premature infants are made to listen during care on stress, oxygen saturation level and length of hospital stay. International Journal of Human Sciences, 11(1), 1343-1359. doi: 10.14687/ijhs.v11i1.2701

listen lullabies for 20-30 minutes and no difference was observed in the respiration values of experiment and control groups. The present study shows parallelism with the studies of these researchers in terms of respiration values. When findings of the research were evaluated in line with the literature (Dagoglu 2002, Hernandez and Thilo 2007), respiration values remained in the normal limits and hypothesis 5 could not be reached.

\section{Discussion of Findings related to the Stress Levels of Infants}

Preterm infants were given stress points which were 1,2, 3 and 0 for mild stress, moderate stress, severe stress and no stress, respectively. Assessment was made through the average stres points.

There exist various studies which measured the stress levels of preterm infants at NICU. When these studies are examined, it is seen that they focused on the effect of music on preterm infants' behaviors, its effect on pain levels, its effect during various care practices and its effect on easy sleeping.

In the study conducted by Whipple (2008), the effects of music during various practices (using nipple, neonatal care etc.) were evaluated and following a 15-minute music therapy, stress indicators decreased dramatically in the group which used nipple and listened lullaby.

Neal (2008), Wood (2008), Desquiotz-Sunnen (2008), Keith et al. (2009) and Hodges \& Wilson (2010) evaluated the effects of music on stress behaviors of preterm infants.

It was determined that there was no statistically significant difference between the first and last stress measurement values of experiment and control groups obtained before the care and at the 30th minute. When the average values of the last stress points were examined, a statistically significant difference was detected between the average values of points recorded before the care and at the 30th minute (p: 0.024). In the experimental group, stress levels of preterm infants decreased considerably but no statistically significance was observed. This difference is thought to have resulted from the fact that infants get accustomed to the music and the familiarity of the music relaxes them (Table 5).

Our study differs from other studies in the literature by the musical genre used therapy, duration of music therapy, its application during care and measurement of different physiological signs. Thus, the present study and its findings related to the stress were interpreted by considering the effects of nursing care accompanying the music therapy. Our study observed no statistically significant decrease in terms of stress indicators as stated in the studies conducted by Hodges \& Wilson (2010) and Wood (2008). It is thought that this finding may have resulted from the musical 
Aydın, D. \& Yıldız, S. (2014). Effect of Turkish music that premature infants are made to listen during care on stress, oxygen saturation level and length of hospital stay. International Journal of Human Sciences, 11(1), 1343-1359. doi: 10.14687/ijhs.v11i1.2701

genre preferred in the study as well as the application of music therapy during such practices as care which arouses stress. As a conclusion, hypothesis 1 could not be reached.

\section{Conclusions and recommendations}

\subsection{Usability of study results}

As a conclusion, it was determined that Turkish music surpressed medium noise in the neonatal intensive care unit and balanced PHR and respiration values. Considering that mothers listen to musical works in line with their cultures and languages in our country, future studies should evaluate the effects of other musical works including traditional lullabies, instrumental musical pieces, mother-woman voice etc. which relax the infant as she/he gets accustomed to listening them in the womb. Music therapy is one of the methods used by nurses at NICUs within the scope of individualised developmental care throughout the world. In our country, nurses should be informed about the use of music at NICUs and further researches should be conducted in this respect.

In line with the results of this study, the newborn nurses should be informed about the use of the Turkish music in newborn intensive care units and different studies using the Turkish music in individualized developmental care applications should be promoted, as well.

\section{References}

1. Ahmadshah, F., Rana, A., Sohalia, K., Habibollah, E., Asraf, M. (2010). The effect of listening to lullaby music on physiologic responce and weight gain of premature infants. Journal of Neonatal Perinatal Medicine, 3(2): 103-7.

2. Almerud, S., Peterson, K. (2003). Music theraphy a complementary treatment for mechanically ventilated intensive care patients. Intensive and Critical Care Nursing, 19(1): 21-30.

3. Altuncu, E., Akman, I., Kulekci, S., Akdag, F., Bilgen, H., Ozek, E. (2009). Noise levels in neonatal intensive care unit and use of sound absorbing panel in the isolette. International journal of pediatric otorbinolaryngology, 73: 951-3.

4. Arnon, S., Shapsa, A., Forman, L., Regev, R., Bauer, S., Litmanovitz, D.T. (2006). Live music is benefical to preterm infants in the neonatal intensive care unit enviroment. Birth, 33(2): 131-6.

5. Aydin, D., Yildiz, S. (2012). Effect of classical music on stress among preterm infants in a neonatal intensive care unit. HealthMED, 6(9): 3176-82.

6. Brad, J., Dileo, C., Grocke, D. (2010). Music interventions for mechanically ventilated patients. Cochrane Database of Systematic Rewriews, 12.

7. Butt, M.L. (1998). The effect of music on preterm infant behaviour. (Unpublished Master Dissertation), Queen's University, Kingston, Canada.

8. Caine, J. (1991). The Effects of Music on the Selected Stress Behaviors, Weight, Caloric and Formula Intake, and Length of Stay of Premature and Low Birthweight Neonates in a Newborn-Intensive Care Unit. Journal of Music Therapy, 28(4): 180-92.

9. Cevasco, A.M. (2008). The effects of mothers ${ }^{\text {ee }}$ singing on full term and preterm infants and maternal emotional responses. Journal of Music Therapy, 45(3): 273-306.

10. Chen, H.L., Chen, C.H., W.U., C.C., Huang, H.J., Wang, T.M., H.S.U. C.C. (2009). The influence of neonatal intensive care unit design on sound level. Pediatr neonatol, 50(6): 270-4. 
Aydın, D. \& Yildız, S. (2014). Effect of Turkish music that premature infants are made to listen during care on stress, oxygen saturation level and length of hospital stay. International Journal of Human Sciences, 11(1), 1343-1359. doi: $10.14687 /$ ijhs.v11i1.2701

11. Courtnage, A. (2001). The effect of live infant directed singing on the heart rate, oxygen saturation level and respiration rate of premature infants in the neonatal intensive care unit. (Unpublished Master Dissertation), MCP Hahnemann University, Philadelphia, Pennsylvania, United States.

12. Çoban, A. (2005). Ruh Sağlı̆̆ı İçin Müzik ile Tedavi-Müzikterapi (Music Therapy and Music Therapy for Mental Health). İstanbul: Timaş Yayınları.

13. Dağoğlu, T. (2002). Yenidoğanın gelişimi ve çevresel faktörler (Development of Infants and environmental factors). In Temel Neonatoloji ve Hemşirelik İlkeleri (Basic Neonatalogy and Nursing Principles) (Dağoğlu T, Görak G ed.), İstanbul: Nobel Tıp Matbaacılık, 729-37.

14. Derebent, E., Yigit, R. (2008). Non-Pharmacological Pain Management In Newborn. Firat University of Health Sciences Journal of Medicine, 22(2): 113-8.

15. Desquiotz-Sunnen, N. (2008). Singing for preterm born infants music therapy in neonatology. Bull Soc Sci Med Grand-Duche Luxembourg, 1: 131-43.

16. Gencel, O. (2006). Müzik ile tedavi (Therapy with music). Kastamonu Training Journal, 14(3): 697-706.

17. Gilad, E., Arnon, S. (2010). The Role of Live Music and Singing as a Stress-Reducing Modality in the Neonatal Intensive Care Unit Environment. Music and Medicine, 2(1): 18-22.

18. Gooding, L.F. (2010). Sing music therapy protocols in the treatment of premature infants: an introduction to current practices. The Arts in Psychotherapy, 37: 211-4.

19. Hartling, L., Shaik, M.S., Tjosvold, L., Leicht, R., Liang, Y., Kumar, M. (2009). Music for medical indications in the neonatal period: a systematic review of randomised controlled trials. Arch Dis Child Fetal Neonatal Ed, 94: 349-54.

20. Hernandez, J., Thilo, E. (2007). Routine care of a mature infant. In M. Yurdakok (Ed.), Pediatrics, Istanbul: Gunes Bookstore, 1277-85.

21. Hodges, A., Wilson, L.L. (2010). Effects of Music Theraphy on preterm infants in the neonatal intensive care unit. Alternative therapies, 16(5): 72-3.

22. Jenkins, J.J. (2001). The Mozart Effect. Journal of the Royal Society of Medicine, 94: 170-2.

23. Kaminski, J. (1996). The effect of soothing music on neonatal behavioral states in hospital newborn nursery. The Journal of Neonatal Nursing, 15: 45-54.

24. Keith, D.R., Russell, K. (2009). The effects of music listening on inconsolable crying in premature infants. Journal of Music Therapy, 46(3): 191-203.

25. Kemper, K.J., Danhauer, S.C. (2005). Music as therapy. Southern Medical Journal, 98(3): 282-86.

26. Kruger, C. (2010). Exposure to maternal voice in preterm infants. Advances in neonatal care, 10(1): 13-8.

27. Lee, G.Y.C. (2010). Fetal and Newborn auditory processing of the motheres and father" soice. (Unpublished Master Dissertation), Queen's University, Canada.

28. Lubetzky, R., Mimouni, F.B., Dollberg, S., Reifen, R., Ashbel, G., Mandel, D. (2010). Effect of music by Mozart on energy expenditure in growing preterm infants. Pediatrics, 125(1): 24-8.

29. Mazer, S.E. (2010). Music, Noise, and the Environment of Care: History, Theory, and Practice. Music and Medicine, 2(3): 182-191.

30. Morris, B.H., Philbin, M.K., Bose, C. (2000). Physiological Effects of Sound on the Newborn. Journal of Perinatology, 20: 54-9.

31. Nair, C., Gupta, G., Jatana, C.S.K. (2003). NICU Environment: Can we be Ignorant? MJAFI, 59: 93-5.

32. Neal, D.O. (2008). Music as a health patterning modality for preterm infants in the NICU. (Unpublished Doctoral Dissertation), The Faculty of The Graduate School of The University of Minnesota.

33. Schwartz, F.J. (1997a). Music Stres Reduction and Medical Cost Savings in the Neonatal İntensive Care Unit. Journal of Prenatal \& Perinatal Psychogy Health, 12(1): 19-29. 
Aydın, D. \& Yıldız, S. (2014). Effect of Turkish music that premature infants are made to listen during care on stress, oxygen saturation level and length of hospital stay. International Journal of Human Sciences, 11(1), 1343-1359. doi: 10.14687/ijhs.v11i1.2701

34. Schwartz, F.J. (1997b). Perinatal stress reduction, music, and medial cost saving. Journal of Prenatal and Perinatal Psychology and Health, 12: 19-29.

35. Somakci, P. (2003). Türklerde Müzik ile Tedavi (Music therapy and the Turks). Journal of the Institute of Social Sciences 15: 131-40.

36. Standley, J.M. (2000). The effect of contingent music to increase non-nutritive sucking of premature infants. Pediatric Nursing, 26: 493-5.

37. Standley, J.M. (2001). Music therapy for the neonate. Newborn and Infant Nursing Reviews, 1: 211 6.

38. Standley, J.M., Swedberg, O. (2010). NICU music therapy: Post hoc analysis of an early intervention clinical program. The Arts in Psychotherapy, 38(1): 36-40.

39. Tari, A. (2003a). Prematüre Bebeklerde Biberonla Beslenmeye Geçiş Sirasında Uygulanan Geleneksel ve Gelişimsel Bakım Yöntemlerinin Karşılaştırılması (Comparison of Traditional and Developmental Care Methods Applied during Transition to Bottlefeeding in Premature Infants). Postgraduate Thesis. Marmara University Institute of Medical Sciences, Istanbul.

40. Tari, A. (2003b). Yenidoğan yoğun bakım ünitelerinde çevrenin değerlendirilmesi ve düzenlenmesi (Assessment and arrangement of the environment in the neonatal intensive care units). In H. Pek (Ed.), Individualized Supportive Developmental Care in Intensive Care Units Course. Istanbul.

41. Thiel, M.T., Findeisen, B., Langler, A. (2011). Music Therapy as Part of Integrative Neonatology: 20 Years of Experience-3 Case Reports and Review. Forsch Komplementmed, 18: 31 5.

42. Whipple, J. (2008). The effect of music-reinforced nonnutritive sucking on state of preterm, low birthweight infants experiencing heelstick. Journal of Music Therapy, 45(3): 227-72.

43. Wood, A.H. (2008). Effect of music therapy on preterm infants in the neonatal intensive care unit. (Unpublished Doctoral Dissertation), The University of Alabama, Birmingham, Alabama. 